\title{
CD133 expression predicts post-operative recurrence in patients with colon cancer with peritoneal metastasis
}

\author{
HIROSHI NAGATA $^{1}$, SOICHIRO ISHIHARA ${ }^{2}$, JUNKO KISHIKAWA $^{3}$, HIROFUMI SONODA $^{1}$, KOJI MURONO $^{1}$, \\ SHIGENOBU EMOTO $^{1}$, MANABU KANEKO ${ }^{1}$, KAZUHITO SASAKI $^{1}$, KENSUKE OTANI $^{1}$, \\ TAKESHI NISHIKAWA ${ }^{1}$, TOSHIAKI TANAKA ${ }^{1}$, TOMOMICHI KIYOMATSU ${ }^{1}$, \\ KEISUKE HATA $^{1}$, KAZUSHIGE KAWAI ${ }^{1}$ and HIROAKI NOZAWA ${ }^{1}$ \\ ${ }^{1}$ Department of Surgical Oncology, The University of Tokyo, Bunkyo-ku, Tokyo 113-8655; \\ ${ }^{2}$ Department of Surgery, International University of Health and Welfare Sanno Hospital, Minato-ku, Tokyo 107-0052; \\ ${ }^{3}$ Department of Surgery, Tohto Bunkyo Hospital, Bunkyo-ku, Tokyo 113-0034, Japan
}

Received October 10, 2017; Accepted January 3, 2018

DOI: 10.3892/ijo.2018.4240

\begin{abstract}
Despite extensive research on cancer stem cells in colorectal cancer, the impact of stem cell markers on patient survival remains unclear, particularly in those with distant metastasis. In this study, we focused on colon cancer with peritoneal metastasis and investigated the association between the expression of CD133, aldehyde dehydrogenase-1 (ALDH1) and leucine-rich repeating G-protein coupled receptor-5 (Lgr5), and disease prognosis. Putative stem cell marker expression was immunohistochemically evaluated in samples from 142 primary tumours and 75 peritoneal nodules. The associations between the expression of these markers and clinicopathological characteristics, overall survival and disease-free survival were analysed. The expression of CD133, ALDH1 and Lgr5 was found to be positive in 55.6, 47.2 and $78.9 \%$ of the primary tumour samples, respectively. While their expression was not associated with overall survival, diseasefree survival was significantly worse in the CD133-negative group (36.1 vs. $13.7 \%, \mathrm{P}=0.041$ ). Multivariable analysis confirmed that a negative CD133 expression was an independent risk factor for a reduced disease-free survival $(\mathrm{P}=0.005)$. Furthermore, the benefit of systemic chemotherapy was significantly greater in the CD133-negative group $(\mathrm{P}=0.039)$. On the whole, our data indicated that patients with colon cancer with CD133-negative expression had a reduced disease-free
\end{abstract}

Correspondence to: Dr Hiroshi Nagata, Department of Surgical Oncology, The University of Tokyo, 7-3-1 Hongo, Bunkyo-ku, Tokyo 113-8655, Japan

E-mail: hinagata-tky@umin.ac.jp

Abbreviations: ALDH1, aldehyde dehydrogenase-1; Lgr5, leucinerich repeating G-protein coupled receptor-5; HIPEC, hyperthermic intraperitoneal chemotherapy; CT, computed tomography; HR, hazard ratio; $\mathrm{CI}$, confidence interval

Key words: cancer stem cell marker, CD133, aldehyde dehydrogenase-1, leucine-rich repeating G-protein coupled receptor-5, colon cancer, peritoneal metastasis survival. Thus, we propose that CD133 expression may be a useful clinical biomarker in the treatment of colon cancer with peritoneal metastasis.

\section{Introduction}

Distant metastasis, a major prognosis determinant in patients with colorectal cancer, is present in approximately one-fifth of all newly diagnosed cases. The 5-year survival of patients who present with synchronous distant metastases is not $>20 \%(1,2)$. Moreover, even if patients are initially diagnosed with nonmetastatic disease, $25-50 \%$ of these patients experience tumour recurrence despite potentially curative resections $(1,3,4)$. In order to improve the prognoses of these patients, it is essential to investigate the aetiology and pathophysiology of metastasis and find an innovative therapeutic strategy.

It has recently been proposed that cancer stem cells play a significant role in tumour progression and metastatic dissemination in various types of cancer (5). A cancer stem cell, defined as 'a cell within a tumour that possesses the capacity to self-renew and to cause the heterogeneous lineages of cancer cells that comprise the tumour' (6), is considered to be an explanation for the resistance of cancer tissues to treatment. Therefore, tumours with high expression levels of cancer stem cell markers are expected to exhibit unfavourable prognoses.

However, the impact of cancer stem cell markers on patient survival remains unclear, particularly in patients with distant metastasis. Our previous study on liver metastasis using CD133, the most well known putative stem cell marker in colorectal cancer, revealed that patients without CD133 expression exhibited reduced survival (7). Although this seemed to contradict the cancer stem cell theory, there are other studies which support these findings $(8,9)$.

Therefore, in this study, we focused on patients with colon cancer with peritoneal metastasis, as this has not been investigated to date, at least to the best of our knowledge. The aim of this study was to determine the impact of cancer stem cell markers on the prognosis of patients with colon cancer with peritoneal metastasis. We also examined 2 other putative stem cell markers, aldehyde dehydrogenase-1 (ALDH1) and 
leucine-rich repeating G-protein coupled receptor-5 (Lgr5), in order to examined whether the findings may be attributed to stemness or whether they are specific to CD133.

\section{Materials and methods}

Patients and tissue specimens. Among 1,990 patients who underwent resection for primary sporadic colon cancer at the University of Tokyo Hospital (Tokyo, Japan) between 1997 and 2015,171 were diagnosed with synchronous or metachronous peritoneal metastasis. Information on these patients and their tumour characteristics, treatments and clinical outcomes were retrieved from patient medical records. During the former half of the study period, the majority of surgeries were performed by an open method, while in the latter half, approximately one third of the surgeries were performed laparoscopically. A total of 55 patients underwent complete resections of recognisable metastases, including visible peritoneal nodules, while the remaining patients had residual tumour tissues. No patients underwent peritonectomy or hyperthermic intraperitoneal chemotherapy (HIPEC).

The study protocol was approved by the Research Ethics Committee at the Graduate School of Medicine, the University of Tokyo (Tokyo, Japan) (approval no. G3552-3). All participants provided informed, written informed consent. This study was conducted in accordance with the 1964 Declaration of Helsinki and its later amendments.

Peri-operative evaluation. All patients were clinically staged by a physical examination, colonoscopy and chestabdomen-pelvis computed tomography (CT) prior to surgery. Pathological staging was performed according to the Union for International Cancer Control TNM Classification of Malignant Tumours, 7th edition (10). Tumours proximal to the splenic flexure were classified as proximal colon cancer and those distal to the splenic flexure were classified as distal colon cancer. Tumours originating in the vermiform appendix and rectum were excluded. In all cases, regular follow-up examinations were performed (tumour marker assessments every 3 months, chest-abdomen-pelvic CT every 6 months and an annual total colonoscopy). Peritoneal metastasis was diagnosed based on surgical exploration or imaging studies. No patient underwent systematic second-look surgery.

Evaluation by immunohistochemistry. Consecutive 3- $\mu \mathrm{m}$-thick formalin-fixed paraffin-embedded sections were immunohistochemically stained manually using the following procedures. Following deparaffinisation and rehydration, endogenous peroxidase was blocked with $3 \%$ hydrogen peroxidase solution in methanol for $15 \mathrm{~min}$. Heat-induced antigen retrieval was performed in $10 \mathrm{mM}$ sodium citrate buffer ( $\mathrm{pH}$ 6.0) using an autoclave. Following non-specific protein blocking by incubation with 5\% bovine serum albumin for $30 \mathrm{~min}$, the slides were incubated overnight with primary antibodies against CD133 (mouse anti-human polyclonal antibody; AC133; 1:100 dilution; Miltenyi Biotec, Auburn, CA, USA), ALDH1 (clone EP1933Y; 1:200 dilution; Abcam, Cambridge, MA, USA) and Lgr5 (clone EPR3065Y; 1:100 dilution; LifeSpan Biosciences, Seattle, WA, USA), in a humidified container at $4^{\circ} \mathrm{C}$. They were then incubated using a Dako Envision kit (Dako, Carpinteria,
CA, USA) and also incubated in 2\% 3,3'-diaminobenzidine tetrahydrochloride and $50 \mathrm{mM}$ tris-buffer containing hydrogen peroxidase as a chromogen following the manufacturer's instructions. Meyer's haematoxylin (Sigma Chemical Co., St. Louis, MO, USA) was used for counterstaining.

Expression was defined as positive when CD133, ALDH1 and Lgr5 staining was found in $>5,20$ and $50 \%$ of the tumour samples, respectively $(7,11,12)$, by examining 1,000 tumour cells in 10 fields (100 cells/field) with high-power (x200) microscopy (11). The evaluation was performed independently by 2 clinicians (H.N. and J.K.) who were blinded to the clinical findings. Discrepancies between their findings were resolved by discussion.

Statistical analysis. Categorical variables were described using frequencies and percentages. Correlation was evaluated using Fisher's exact test or a Chi-squared test. The distributions of continuous variables were described using medians and the interquartile ranges. The Mann-Whitney test was used for comparisons. Overall survival was defined as the duration between the date of primary tumour resection and the date of death from any cause. Disease-free survival was defined as the duration between the date of complete resection for metastasis and the date of recurrence or death from any cause. These outcomes were calculated using the Kaplan-Meier method and compared using the log-rank test. Univariate and multivariate Cox regression analyses were performed to investigate patient and tumour characteristics associated with the prognosis of metachronous peritoneal metastasis. The variables for multivariate analysis were selected using the model selection approach by Collett (13). Through the time-to-event analysis, hazard ratios (HRs) and 95\% confidence intervals (CIs) were generated. Associations were considered significant for P-values $<0.05$ in general; however, a level of significance of 0.15 was used for Collett's univariable screening (13). Data were statistically analysed using the statistical program $\mathrm{R}$ version 3.3.1 (http://www.R-project.org/).

\section{Results}

Immunohistochemical expression in primary tumours and clinicopathological variables. Specimens of 142 cases were available for the immunohistological evaluation of primary tumours, and those of 75 cases were available for the evaluation of metastatic peritoneal nodules, as shown in Fig. 1. The immunohistochemical staining pattern of CD133, ALDH1, and Lgr5 is shown in Fig. 2. Membranous immunoreactivity was observed for CD133, and cytoplasmic immunoreactivity was observed for ALDH1 and Lgr5. The rates of the positive expression of CD133, ALDH1 and Lgr5 in our primary tumour samples were $55.6 \%$ (79/142), 47.2\% (67/142) and $78.9 \%$ (112/142), respectively.

The clinicopathological characteristics of the patients are shown in Table I. Concurrent distant metastasis was found in 59 patients. While 33 of these patients had a single organ metastasis other than the peritoneum, 20 patients had 2, and 6 patients had more than 3 sites of metastasis in addition to the peritoneum. The most common site of metastasis was the liver ( 35 patients), followed by the lung (20 patients), the distant lymph nodes (19 patients) and the ovary (6 patients). 


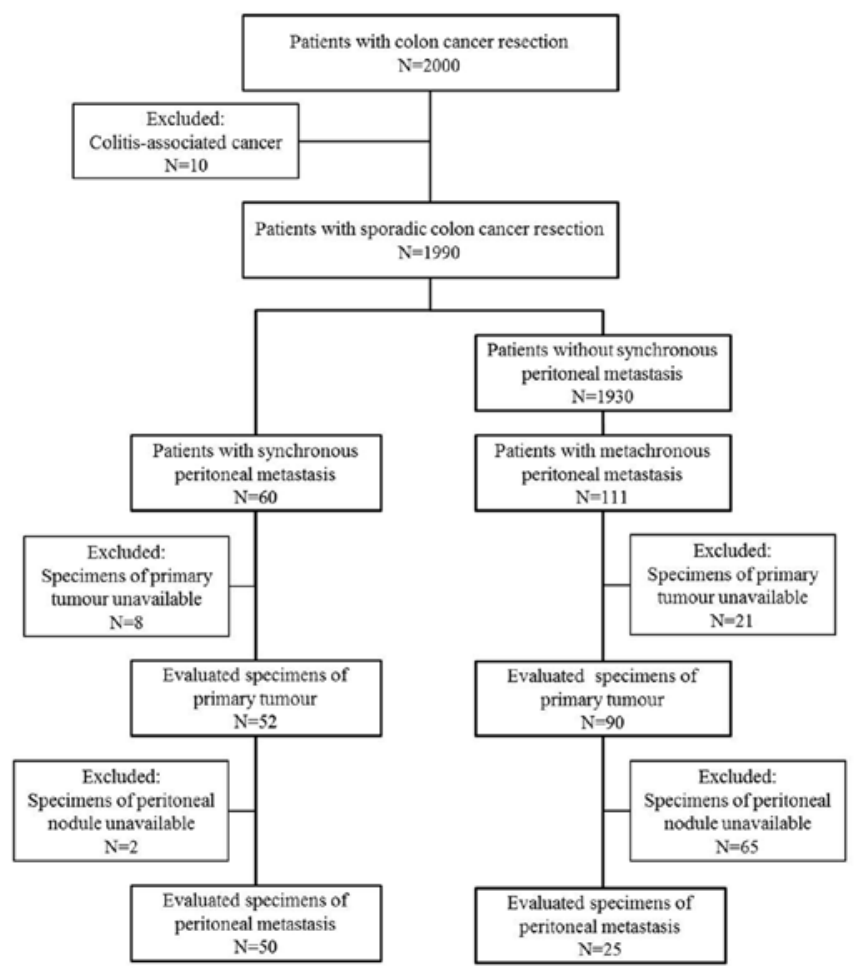

Figure 1. Flow chart for the selection of specimens.

With regards to adjuvant chemotherapy following the resection of the peritoneal nodules, 5-fluorouracil regimens were used in 16 patients and cytotoxic doublet regimens were used in 20 patients.

The expression levels of CD133 and Lgr5 were significantly lower in the mucinous adenocarcinoma samples $(\mathrm{P}<0.001$ and $\mathrm{P}=0.020)$. In addition, the expression of $\mathrm{CD} 133$ significantly correlated with differentiation $(\mathrm{P}<0.001)$ and the $\mathrm{N}$ category $(\mathrm{P}=0.002)$, and the percentage of complete resection was significantly lower in the Lgr5-negative group $(\mathrm{P}=0.002)$ (Table I).

Immunohistochemical expression in primary tumours and prognosis. The median overall survival of the patients with peritoneal metastasis was 24.6 months, and the 5-year overall survival rate was $22.0 \%$ among all patients. The expression of CD133, ALDH1 and Lgr5 was not associated with overall survival (29.7 vs. $12.7 \%, \mathrm{P}=0.158$ for $\mathrm{CD} 133$; 20.2 vs. $23.8 \%$, $\mathrm{P}=0.553$ for $\mathrm{ALDH} 1$; and 19.4 vs. $31.1 \%, \mathrm{P}=0.086$ for Lgr5) (Fig. 3A-C). Similar results were observed when the patient subgroups were stratified according to the completeness of metastasectomy $(\mathrm{P}=0.123, \mathrm{P}=0.265$ and $\mathrm{P}=0.619$ for CD133, ALDH1 and Lgr5, respectively, in the patients with complete resection, and $\mathrm{P}=0.956, \mathrm{P}=0.993$ and $\mathrm{P}=0.718$ for CD133, ALDH1 and Lgr5, respectively, in the patients with residual metastasis) (Fig. 4).

The median disease-free survival of 55 patients who underwent complete resection was 16.0 months and the 5-year disease-free survival rate for these patients was $27.2 \%$. The most common site of recurrence was the lung (5 patients), followed by the peritoneum, liver and distant lymph nodes (4 patients for each). While no significant difference was observed in the expression of ALDH1 and Lgr5 (31.2 vs. 24.1\%,

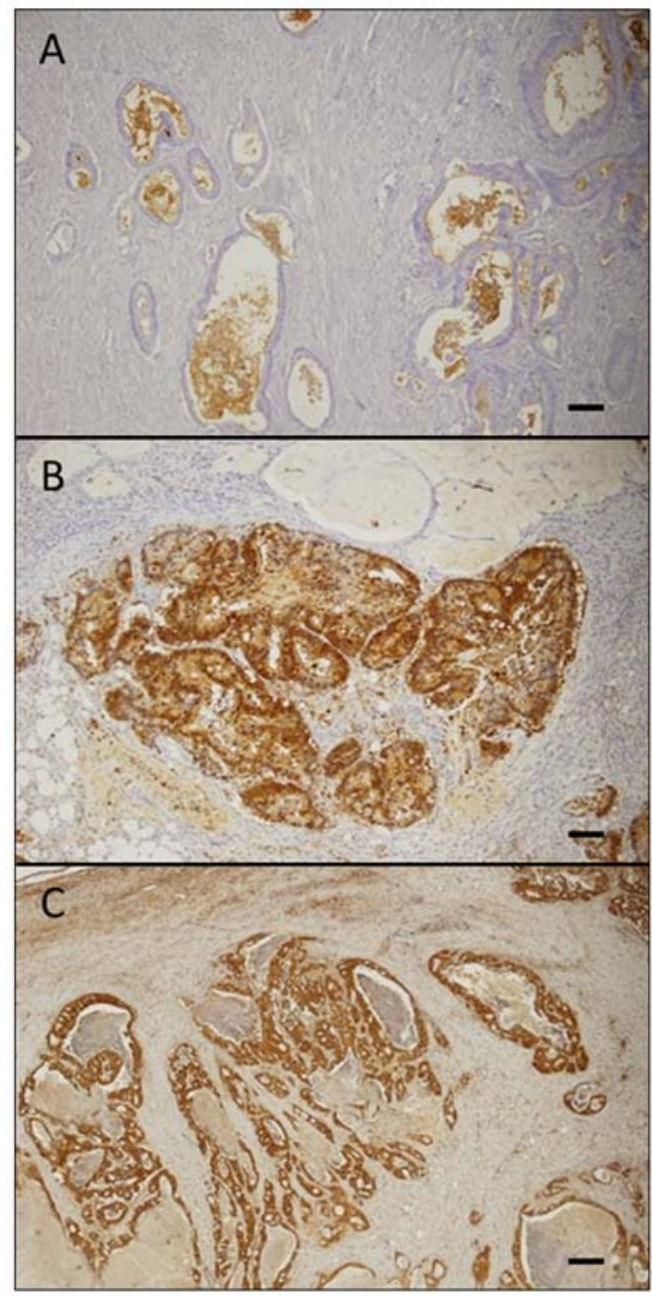

Figure 2. Expression of cancer stem cell markers by immunohistochemical staining. (A) CD133, (B) aldehyde dehydrogenase-1 (ALDH1) and (C) leucine-rich repeating G-protein coupled receptor-5 (Lgr5) (original magnification, $\mathrm{x} 200$; scale bars, $100 \mu \mathrm{m}$ )

$\mathrm{P}=0.433$ for $\mathrm{ALDH} 1$ and 23.6 vs. $33.3 \%, \mathrm{P}=0.236$ for $\mathrm{Lgr} 5)$, a positive expression of CD133 was associated with a significantly improved 5-year disease-free survival (36.1 vs. 13.7\%, $\mathrm{P}=0.041$ ) (Fig. 3D-F).

The Cox multivariate model selected using the Collett's model selection approach contained age, adjuvant chemotherapy following peritoneal nodule resection, and the expression of CD133. A positive CD133 expression was found to be a significant positive factor for disease-free survival (HR, 0.33; 95\% CI, 0.16-0.72, $\mathrm{P}=0.005$ ) as was adjuvant chemotherapy (HR, 0.23; 95\% CI, 0.10-0.52, P<0.001) and older age (HR, 0.24; 95\% CI, 0.08-0.63 for patients aged 50-69 years; and HR, $0.16,95 \%$ CI, $0.05-0.48$ for patients aged $\geq 70$ years, $\mathrm{P}=0.003$ ) (Table II).

Immunohistochemical expression in peritoneal nodules and clinicopathological variables. The rate of the positive expression of CD133, ALDH1 and Lgr5 was 40.0\% (30/75), 30.7\% $(23 / 75)$ and $78.6 \%(59 / 75)$, respectively, in our peritoneal nodule samples. The expression of CD133 and ALDH1 in the peritoneal nodules was significantly lower than that in the primary tumour samples $(\mathrm{P}=0.002$ and $\mathrm{P}=0.001$, respectively), while that of $\operatorname{Lgr} 5$ did not differ significantly $(P=0.207)$. 
Table I. Clinicopathological characteristics of the patients from whom primary tumour samples were obtained.

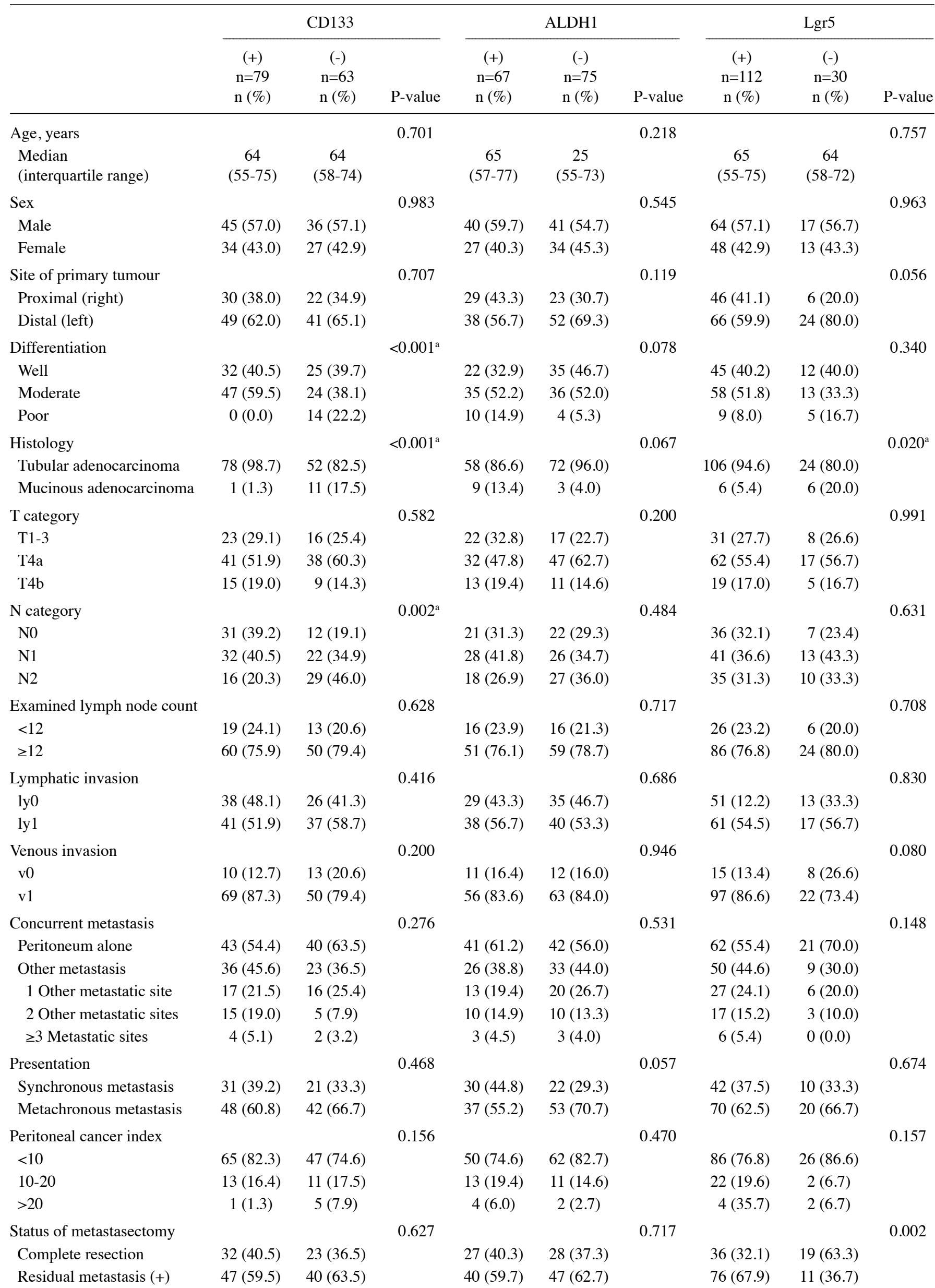


Table I. Continued.

\begin{tabular}{|c|c|c|c|c|c|c|c|c|c|}
\hline & \multicolumn{3}{|c|}{ CD133 } & \multicolumn{3}{|c|}{ ALDH1 } & \multicolumn{3}{|c|}{ Lgr5 } \\
\hline & $\begin{array}{c}(+) \\
\mathrm{n}=79 \\
\mathrm{n}(\%)\end{array}$ & $\begin{array}{c}(-) \\
\mathrm{n}=63 \\
\mathrm{n}(\%)\end{array}$ & P-value & $\begin{array}{c}(+) \\
\mathrm{n}=67 \\
\mathrm{n}(\%)\end{array}$ & $\begin{array}{c}(-) \\
\mathrm{n}=75 \\
\mathrm{n}(\%)\end{array}$ & P-value & $\begin{array}{c}(+) \\
\mathrm{n}=112 \\
\mathrm{n}(\%)\end{array}$ & $\begin{array}{c}(-) \\
\mathrm{n}=30 \\
\mathrm{n}(\%)\end{array}$ & P-value \\
\hline $\begin{array}{l}\text { Chemotherapy after } \\
\text { metastasectomy }\end{array}$ & & & 0.544 & & & 0.853 & & & 0.795 \\
\hline Adjuvant chemotherapy (-) & $10(12.7)$ & $9(14.3)$ & & $9(13.4)$ & $10(13.3)$ & & $12(10.7)$ & $7(23.4)$ & \\
\hline Adjuvant chemotherapy (+) & $22(27.8)$ & $14(22.2)$ & & $18(26.9)$ & $18(24.0)$ & & $24(21.4)$ & $12(40.0)$ & \\
\hline b5-FU & $12(15.1)$ & $4(6.3)$ & & $4(6.0)$ & $12(16.0)$ & & $11(9.8)$ & $5(16.7)$ & \\
\hline${ }^{\mathrm{c}} \mathrm{FOLFOX} /{ }^{\mathrm{d}} \mathrm{CapeOX}$ & $10(12.7)$ & $10(15.9)$ & & $14(20.9)$ & $6(8.0)$ & & 13 (11.6) & $7(23.3)$ & \\
\hline
\end{tabular}

${ }^{a}$ Indicates statistical significance $(\mathrm{P}<0.05)$; ${ }^{\mathrm{b}}$-fluorouracil; ${ }^{\mathrm{c}}$ folinic acid, 5-fluorouracil and oxaliplatin; ${ }^{\mathrm{d}}$ capecitabine and oxaliplatin.

A

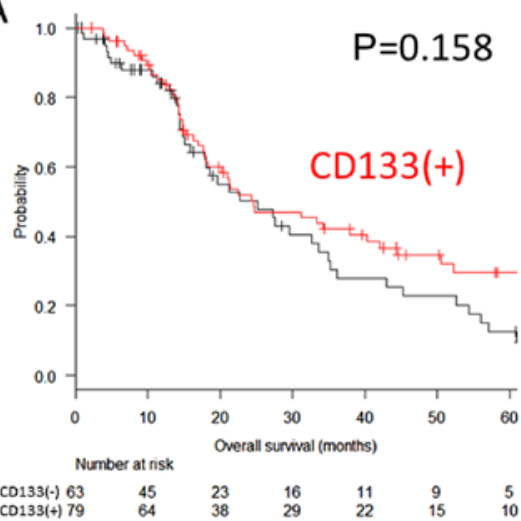

B

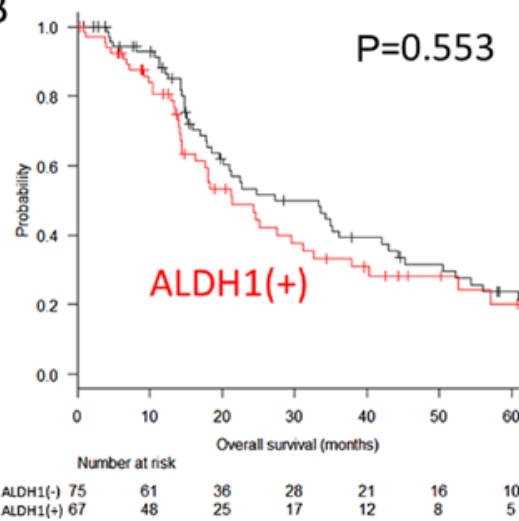

$\mathrm{C}$



D

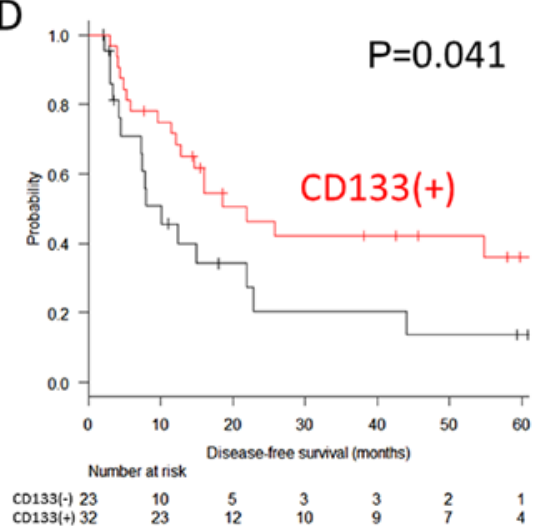

$\mathrm{E}$

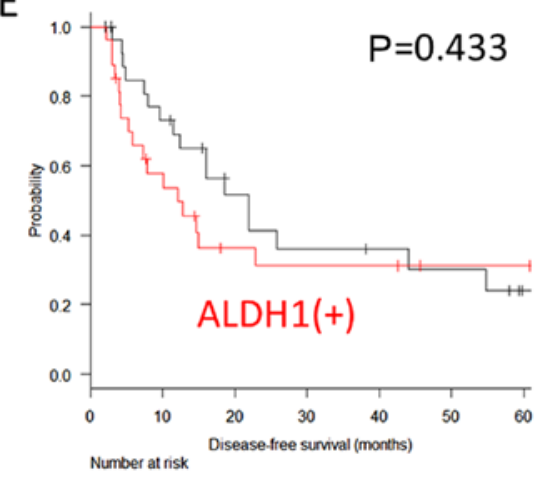

$\begin{array}{lllllll}\text { ALOH1(-) } 28 & 19 & 10 & 7 & 6 & 5 & 1 \\ \text { ALOH1(+) } 27 & 14 & 7 & 6 & 6 & 4 & 4\end{array}$

F

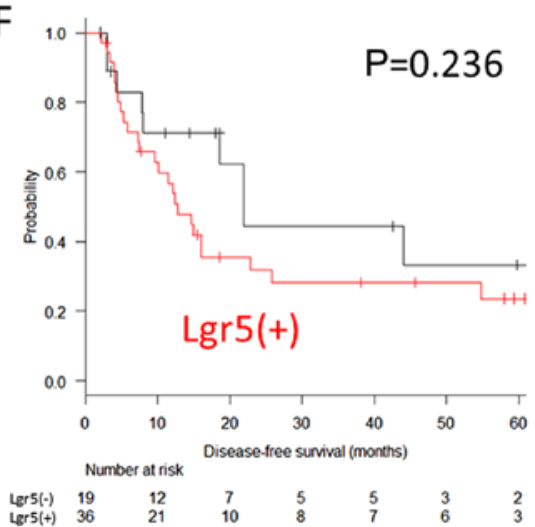

Figure 3. Association of stem cell marker expression levels in primary tumours with prognosis. Overall survival according to the expression of (A) CD133, (B) aldehyde dehydrogenase-1 (ALDH1), and (C) leucine-rich repeating G-protein coupled receptor-5 (Lgr5). Disease-free survival according to the expression of (D) CD133, (E) ALDH1, and (F) Lgr5. 
Table II. Association between clinicopathological variables and disease-free survival.

\begin{tabular}{|c|c|c|c|c|c|c|}
\hline & \multicolumn{3}{|c|}{ Univariate analysis } & \multicolumn{3}{|c|}{ Multivariate analysis } \\
\hline & HR & $95 \% \mathrm{CI}$ & $\mathrm{P}$-value & HR & $95 \% \mathrm{CI}$ & P-value \\
\hline Age, years & & & 0.174 & & & 0.003 \\
\hline$<50$ & Reference & & & Reference & & \\
\hline $50-69$ & 0.45 & $0.17-1.16$ & & 0.23 & $0.09-0.63$ & \\
\hline$\geq 70$ & 0.39 & $0.13-1.13$ & & 0.16 & $0.05-0.48$ & \\
\hline Sex & & & 0.462 & & & \\
\hline Male & Reference & & & & & \\
\hline Female & 1.30 & $0.65-2.60$ & & & & \\
\hline Site of primary tumour & & & 0.254 & & & \\
\hline Proximal (right) & Reference & & & & & \\
\hline Distal (left) & 0.66 & $0.32-1.35$ & & & & \\
\hline Differentiation & & & 0.086 & & & \\
\hline Well & Reference & & & & & \\
\hline Moderate & 1.54 & $0.74-3.18$ & & & & \\
\hline Poor & 3.55 & $1.14-11.05$ & & & & \\
\hline Histology & & & 0.465 & & & \\
\hline Tubular adenocarcinoma & Reference & & & & & \\
\hline Mucinous adenocarcinoma & 1.56 & $0.47-5.14$ & & & & \\
\hline T category & & & 0.937 & & & \\
\hline $\mathrm{T} 3$ & Reference & & & & & \\
\hline $\mathrm{T} 4 \mathrm{a}$ & 1.08 & $0.49-2.35$ & & & & \\
\hline $\mathrm{T} 4 \mathrm{~b}$ & 0.90 & $0.27-2.91$ & & & & \\
\hline $\mathrm{N}$ category & & & 0.281 & & & \\
\hline No & Reference & & & & & \\
\hline N1 & 1.41 & $0.54-3.70$ & & & & \\
\hline $\mathrm{N} 2$ & 2.10 & $0.80-5.48$ & & & & \\
\hline No. of examined lymph nodes & & & 0.555 & & & \\
\hline$<12$ & Reference & & & & & \\
\hline$\geq 12$ & 0.77 & $0.32-1.86$ & & & & \\
\hline Lymphatic invasion & & & 0.291 & & & \\
\hline ly0 & Reference & & & & & \\
\hline ly 1 & 1.45 & $0.73-2.88$ & & & & \\
\hline Venous invasion & & & 0.881 & & & \\
\hline $\mathrm{v} 0$ & Reference & & & & & \\
\hline v1 & 0.92 & $0.32-2.63$ & & & & \\
\hline Concurrent metastasis & & & 0.548 & & & \\
\hline Peritoneum alone & Reference & & & & & \\
\hline Other metastasis & 0.75 & $0.29-1.93$ & & & & \\
\hline Presentation of peritoneal metastasis & & & 0.599 & & & \\
\hline Synchronous & Reference & & & & & \\
\hline Metachronous & 0.83 & $0.42-1.64$ & & & & \\
\hline Adjuvant chemotherapy & & & $0.012^{\mathrm{a}}$ & & & $<0.001^{\mathrm{a}}$ \\
\hline Adjuvant (-) & Reference & & & Reference & & \\
\hline Adjuvant (+) & 0.40 & $0.20-0.82$ & & 0.23 & $0.10-0.52$ & \\
\hline CD133 expression & & & $0.045^{\mathrm{a}}$ & & & $0.005^{\mathrm{a}}$ \\
\hline CD133(-) & Reference & & & Reference & & \\
\hline CD133(+) & 0.50 & $0.25-0.99$ & & 0.33 & $0.16-0.72$ & \\
\hline
\end{tabular}


A

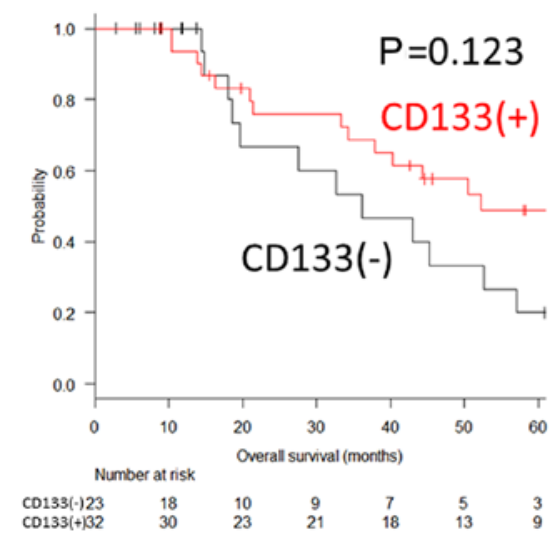

B

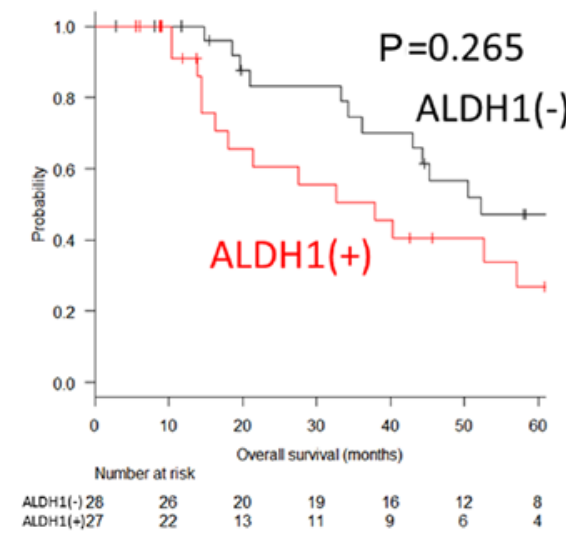

C

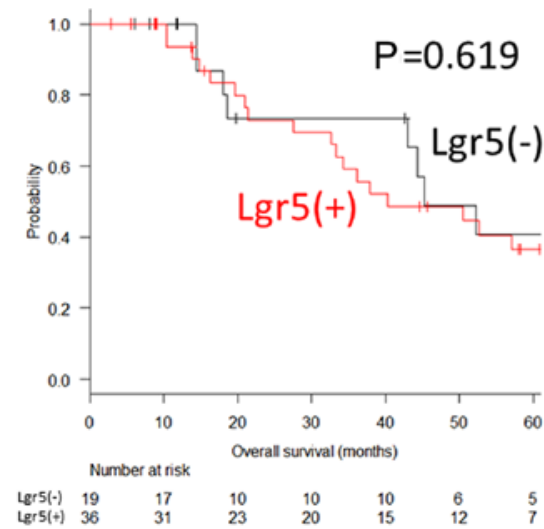

D

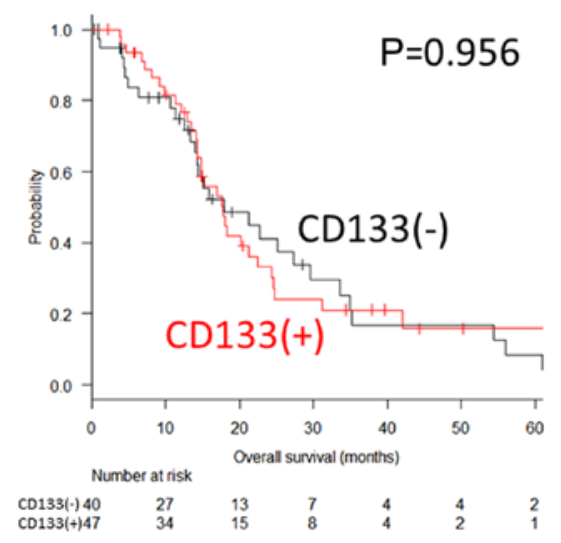

$E$

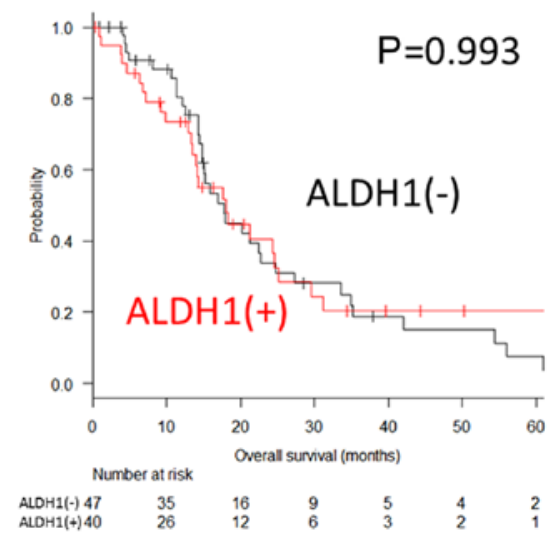

$\mathrm{F}$

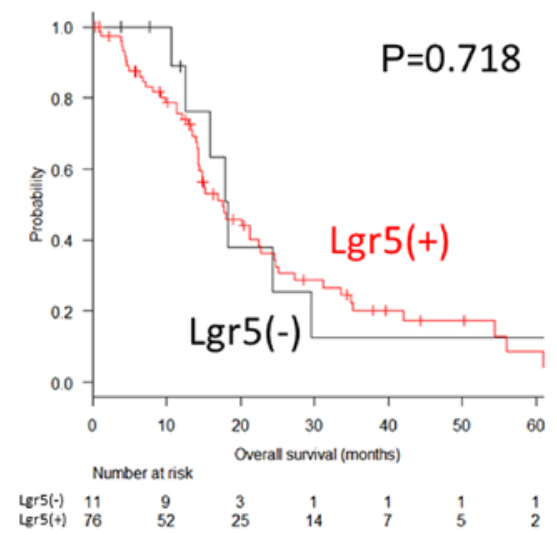

Figure 4. Association of stem cell marker expression levels in primary tumours with overall survival by the completeness of metastasectomy. Overall survival of patients with complete resection of metastasis according to the expression of (A) CD133, (B) aldehyde dehydrogenase-1 (ALDH1), and (C) leucine-rich repeating G-protein coupled receptor-5 (Lgr5). Overall survival of patients with residual metastasis according to the expression of (D) CD133, (E) ALDH1 and (F) Lgr5.

The clinicopathological characteristics of the patients with peritoneal metastasis are shown in Table III. CD133-negative peritoneal nodules significantly correlated with differentiation $(\mathrm{P}=0.0030)$, but not with mucinous adenocarcinoma $(\mathrm{P}=0.392)$ or the $\mathrm{N}$ category $(\mathrm{P}=0.119)$. The number of patients with $<12$ examined lymph nodes was higher in those with ALDH1-negative peritoneal nodules $(\mathrm{P}=0.016)$.

Immunohistochemical expression in peritoneal nodules and prognosis. The impact of immunohistochemical expression in peritoneal nodules on prognosis was similar to that of the primary tumour. The expression of CD133, ALDH1 and Lgr5 was not associated with overall survival (46.4 vs. $20.9 \%$, $\mathrm{P}=0.617$ for $\mathrm{CD} 133$; 35.7 vs. $26.9 \%, \mathrm{P}=0.576$ for $\mathrm{ALDH} 1$; and 29.0 vs. $34.8 \%, \mathrm{P}=0.679$ for $\mathrm{Lgr5}$ ) (Fig. 5A-C). By contrast, the 5-year disease-free survival after complete surgery was significantly superior in the patients with CD133-positive peritoneal nodules (39.5 vs. $22.4 \%, \mathrm{P}=0.040$ ). However, no significant difference was observed in the expression of ALDH1 and Lgr5 in peritoneal nodules (27.9 vs. $34.7 \%$, $\mathrm{P}=0.906$ for $\mathrm{ALDH} 1$; and 27.5 vs. $45.8 \%, \mathrm{P}=0.767$ for Lgr5) (Fig. 5D-F). 
Table III. Clinicopathological characteristics of the patients with peritoneal nodules.

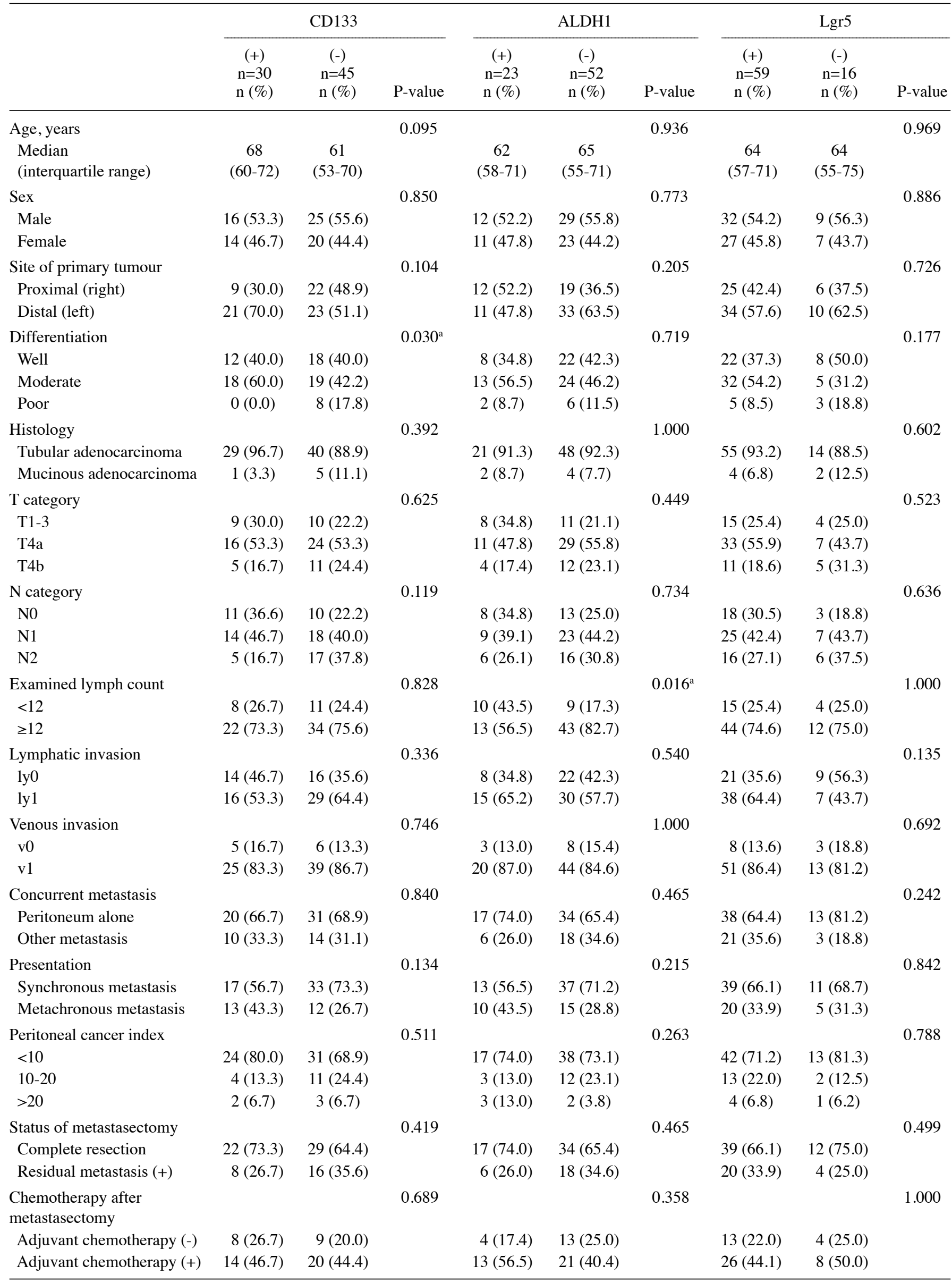

${ }^{a}$ Indicates statistical significance $(\mathrm{P}<0.05)$. 
A



B

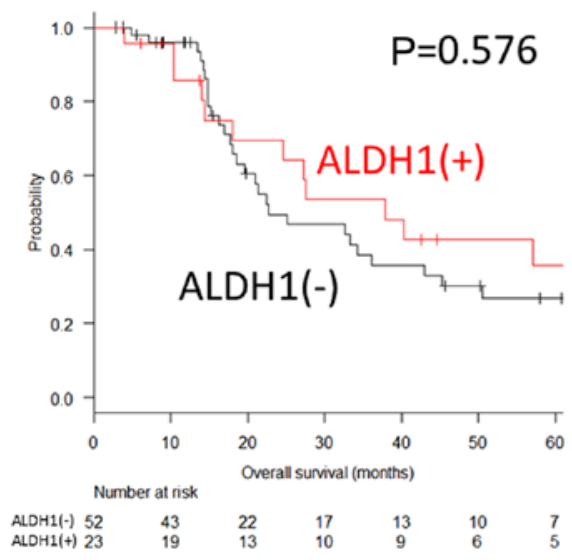

C

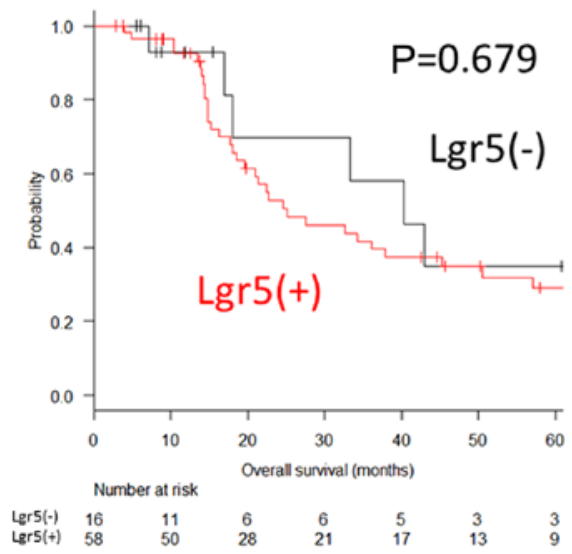

D

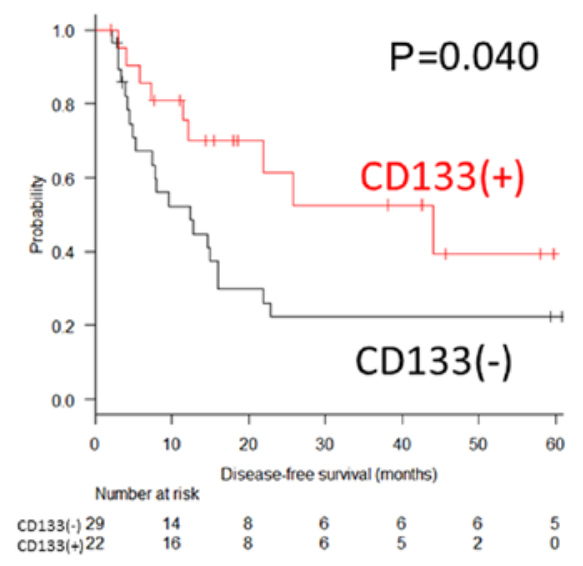

$\mathrm{E}$

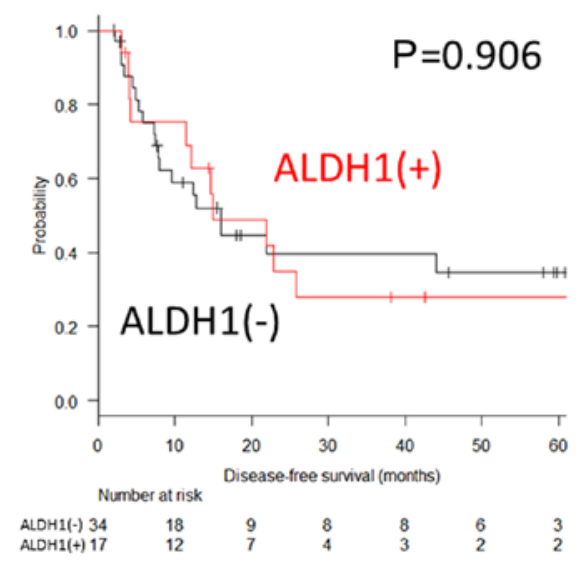

$\mathrm{F}$

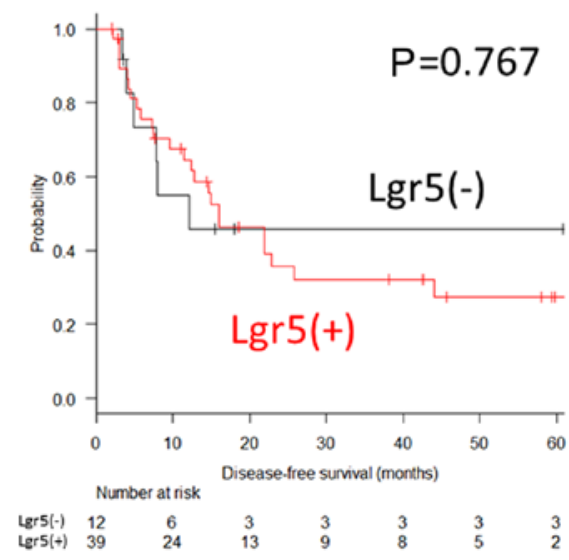

Figure 5. Association of stem cell marker expression levels in peritoneal nodules with prognosis. Overall survival according to the expression of (A) CD133, (B) aldehyde dehydrogenase-1 (ALDH1), and (C) leucine-rich repeating G-protein coupled receptor-5 (Lgr5). Disease-free survival according to the expression of (D) CD133, (E) ALDH1, and (F) Lgr5.

The CD133 expression patterns were clearly associated with disease-free survival. The optimal survival was observed when both the primary tumour and peritoneal nodules were CD133-positive (double positive, Fig. 6), and this was followed by the survival of patients with CD133 positivity either in the primary tumour or peritoneal nodules (single positive). The worst survival was observed when CD133 expression was negative in both the primary tumour and peritoneal nodule (double negative) $(49.8,33.0$ and 13.7\%, respectively; P-value for the trend, $\mathrm{P}=0.011$ ) (Fig. 7).
CD133 expression and chemosensitivity. We further evaluated the sensitivity to chemotherapy according to CD133 expression. Systemic chemotherapy significantly improved the overall survival of the CD133-negative group (HR, 0.19; 95\% CI, 0.07-0.50, $\mathrm{P}<0.001)$ while the risk reduction in the CD133-positive group was not statistically significant (HR, 0.61; 95\% CI, 0.27-1.38, P=0.231). Furthermore, the positive impact of systemic chemotherapy in the CD133-negative group was significantly greater than that in the CD133-positive group ( $\mathrm{P}$-value for the interaction, $\mathrm{P}=0.039$ ). 


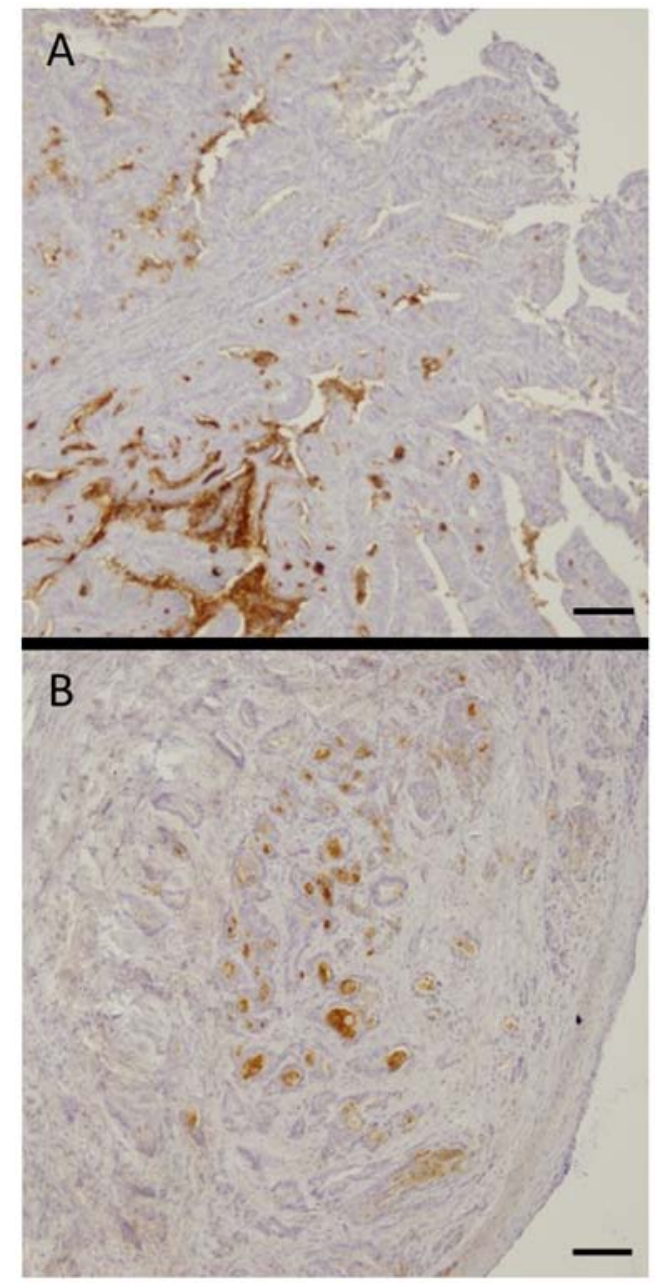

Figure 6. CD133 staining pattern in (A) a primary tumour and (B) a peritoneal nodule (original magnification, x100; scale bars, $100 \mu \mathrm{m}$ ).

With regard to adjuvant chemotherapy following resection, the risk reduction in disease-free survival was statistically significant only in the CD133-negative group (HR, 0.48; 95\% CI, 0.18-1.25, $\mathrm{P}=0.132$ in the $\mathrm{CD} 133$-positive group; and HR, 0.24; 95\% CI, 0.07-0.80, $\mathrm{P}=0.021$ in the CD133-negative group). However, the impact was not statistically significant between the 2 groups ( $\mathrm{P}$-value for the interaction, $\mathrm{P}=0.345$ ).

\section{Discussion}

In this study, we investigated the expression of 3 cancer stem cell markers in patients with colon cancer with peritoneal metastasis, and revealed that CD133-negative patients had a reduced disease-free survival following resection. To the best of our knowledge, this is the first study to examine the impact of stem cell marker expression on the prognosis of patients with colon cancer with peritoneal metastasis. Additionally, we found that patients with CD133-negative disease were more sensitive to chemotherapy than those with CD133-positive disease. Therefore, our data suggest that CD133 may be a useful clinical biomarker for the selection of patients who may receive optimal benefits from adjuvant chemotherapy following metastasectomy.

The impact of CD133 on survival has not yet been fully clarified. Based on the cancer stem cell theory, CD133-positive

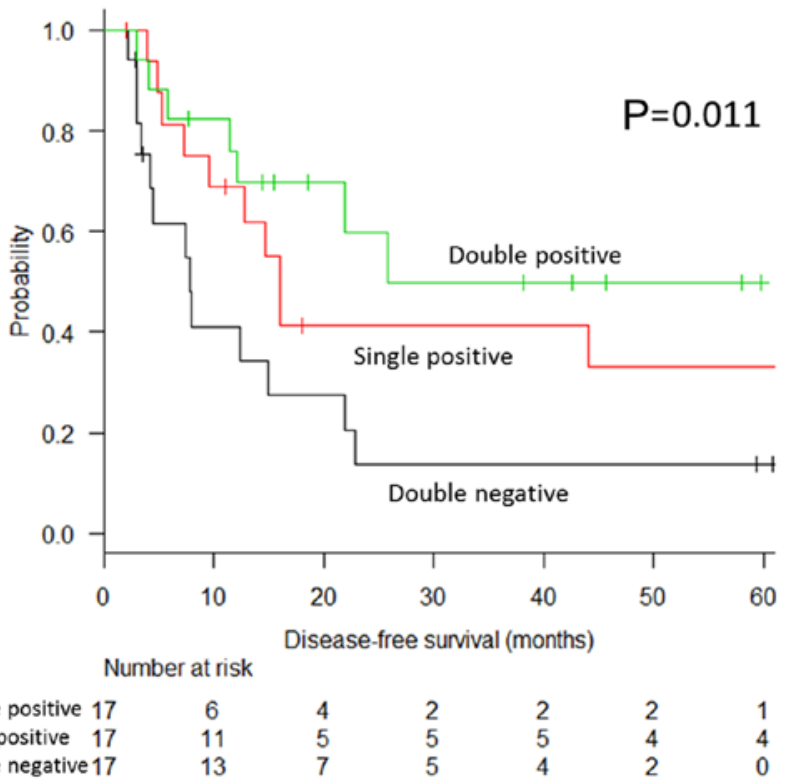

Figure 7. Association of the expression pattern of CD133 and disease-free survival. Double positive, both primary tumour and peritoneal nodules are CD133-positive; single positive, either primary tumour or peritoneal nodules are CD133-positive; double negative, both primary tumour and peritoneal nodules are CD133-negative.

tumours should have a worse prognosis. In fact, a number of studies, including 2 meta-analyses, have shown reduced overall survival in patients with CD133-positive colorectal cancer (14-17). However, studies on liver metastasis of colorectal origin have reported contradictory results, suggesting that the absence of CD133 expression is associated with a poor prognosis (7-9), which is consistent with our finding.

In the present study, we demonstrated that the CD133-negative group had a higher risk of recurrence following the resection of peritoneal metastasis. We employed 2 other stem cell markers, ALDH1 and Lgr5, in order to evaluate the impact of stemness, as CD133 cannot be designated as a definitive marker of stemness. For instance, while CD133-positive cells have been reported to have higher tumour initiation ability, CD133-negative subsets can also initiate tumours (18). Considering that a similar impact was not recognised in the expression of ALDH1 and Lgr5, the significance of CD133 identified in this study was presumed to be caused by CD133-specific factors other than stemness.

Although the findings on the function of CD133 are limited, in vitro studies have reported that E-cadherin expression is significantly lower (8) and that $\beta 1$-integrin expression is higher (19) in CD133-negative cells than in CD133-positive cells. Other studies have found that CD133 is mainly expressed in well- and moderately-differentiated adenocarcinomas, and that $\mathrm{CD} 133$ negativity may reflect a more undifferentiated state $(20,21)$, which is consistent with our findings. Therefore, CD133-negative cells may have a greater capacity to induce metastasis and recurrence than CD133-positive cells.

By contrast, we demonstrated in this study that the benefit of systemic chemotherapy was more evident in CD133-negative disease than in CD133-positive disease, which was consistent with the findings of previous studies $(22,23)$. This difference in chemosensitivity may explain why the CD133-negative 
group was not inferior to the CD133-positive group in terms of overall survival, despite the higher risk of recurrence.

To the best of our knowledge, this is the first study to examine the expression of cancer stem cell markers in nodules of peritoneal metastasis. We found that the expression rate of CD133 and ALDH1 was lower in peritoneal nodules than in primary tumours. The result was contrary to our assumption prior to the study, in that we had considered that the expression of cancer stem cell marker would be higher in peritoneal nodules, since each nodule should have a tumour initiation ability and peritoneal metastasis was known to be resistant to chemotherapy. The reason for the low expression is not clear; however, it may be related to the characteristics of CD133-negative cells that we described earlier. In particular, $\beta 1$-integrin is known to be a key factor for developing peritoneal metastasis (24). ALDH1, in contrast, is a detoxifying enzyme contributing to differentiation and proliferation (25). It may represent the slow-growing nature of peritoneal nodules of colon cancer.

A major limitation of the present study was that none of our patients underwent peritonectomy or HIPEC, which is performed in specialised centres as an effective treatment for peritoneal metastasis of colorectal origin (26). Since the procedure has not been popular in the Japanese clinical setting, we have been performing macroscopic peritoneal nodule resection and have reported the survival benefit (27). Although our findings cannot be directly applied to patients who underwent peritonectomy and HIPEC, we speculate that the CD133 expression pattern may also be a useful indicator of recurrence risk in patients who undergo peritonectomy and HIPEC.

Another limitation is that the evaluation method of CD133 expression widely varies according to different reports, particularly in terms of the anti-CD133 antibody and the cut-off value $(14,15)$. We believe that the immunohistochemical evaluation of CD133 is clinically practicable since the antibody is easily available and the analysis can be performed in many medical facilities. However, as variation in the evaluation method can cause inconsistent outcomes, standardised assessment criteria should be established. In addition, due to the small sample size of the study, the significance of ALDH1 and Lgr5 may be underestimated. Therefore, the findings of this study require confirmation in a larger patient cohort.

In conclusion, in this study, we demonstrated that a negative CD133 expression was a significant risk factor for post-operative recurrence following resection in patients with colon cancer with peritoneal metastasis. In addition, we also found that CD133-negative tumours were more sensitive to chemotherapy than CD133-positive ones. Our data suggest that CD133 expression may be a useful clinical biomarker in the treatment of peritoneal metastasis of colon cancer; however, the oncological function of CD133 requires further clarifications in future studies.

\section{Acknowledgements}

This study was supported by Grants-in-Aid for Scientific Research from Japan Society for the Promotion of Science (grant nos. 16H02672, 16K07143, 16K07161, 17K10620, 17K10621 and 17K10623) and the Project for Cancer Research and Therapeutic Evolution from the Japan Agency for Medical Research and Development (grantno. 16cm0106502h0001). The authors would like to thank Editage (http://www.editage.com) for editing and reviewing this manuscript for English language.

\section{Competing interests}

The authors declare that they have no competing interests.

\section{References}

1. Watanabe T, Muro K, Ajioka Y, Hashiguchi Y, Ito Y, Saito Y, Hamaguchi T, Ishida $\mathrm{H}$, Ishiguro M, Ishihara S, et al; Japanese Society for Cancer of the Colon and Rectum: Japanese Society for Cancer of the Colon and Rectum (JSCCR) guidelines 2016 for the treatment of colorectal cancer. Int J Clin Oncol: Mar 27, 2017 (Epub ahead of print). doi: 10.1007/s10147-017-1101-6.

2. Siegel RL, Miller KD and Jemal A: Cancer Statistics, 2017. CA Cancer J Clin 67: 7-30, 2017.

3. Steele SR, Chang GJ, Hendren S, Weiser M, Irani J, Buie WD and Rafferty JF; Clinical Practice Guidelines Committee of the American Society of Colon and Rectal Surgeons: Practice guideline for the surveillance of patients after curative treatment of colon and rectal cancer. Dis Colon Rectum 58: 713-725, 2015.

4. Van Cutsem E, Cervantes A, Adam R, Sobrero A, Van Krieken JH, Aderka D, Aranda Aguilar E, Bardelli A, Benson A, Bodoky G, et al: ESMO consensus guidelines for the management of patients with metastatic colorectal cancer. Ann Oncol 27: 1386-1422, 2016.

5. Vermeulen L, de Sousa e Melo F, Richel DJ and Medema JP: The developing cancer stem-cell model: Clinical challenges and opportunities. Lancet Oncol 13: e83-e89, 2012.

6. Clarke MF, Dick JE, Dirks PB, Eaves CJ, Jamieson CH, Jones DL, Visvader J, Weissman IL and Wahl GM: Cancer stem cells - perspectives on current status and future directions: AACR Workshop on cancer stem cells. Cancer Res 66: 9339-9344, 2006.

7. Kishikawa J, Kazama S, Oba K, Hasegawa K, Anzai H, Harada Y, Abe H, Matsusaka K, Hongo K, Oba M, et al: CD133 Expression at the metastatic site predicts patients' outcome in colorectal cancer with synchronous liver metastasis. Ann Surg Oncol 23: 1916-1923, 2016

8. Yamamoto S, Tanaka K, Takeda K, Akiyama H, Ichikawa Y, Nagashima Y and Endo I: Patients with CD133-negative colorectal liver metastasis have a poor prognosis after hepatectomy. Ann Surg Oncol 21: 1853-1861, 2014.

9. Pitule P, Cedikova M, Daum O, Vojtisek J, Vycital O, Hosek P, Treska V,Hes O,Kralickova M and Liska V: Immunohistochemical detection of cancer stem cell related markers CD44 and CD133 in metastatic colorectal cancer patients. BioMed Res Int 2014: 432139, 2014

10. Sobin LH, Gospodarowicz MK and Wittekind C: TNM Classification of Malignant Tumours.7th edition. Wiley-Blackwell, West Sussex, 2010

11. Maeda S, Shinchi H, Kurahara H, Mataki Y, Maemura K, Sato M, Natsugoe S, Aikou T and Takao S: CD133 expression is correlated with lymph node metastasis and vascular endothelial growth factor- $\mathrm{C}$ expression in pancreatic cancer. $\mathrm{Br} \mathrm{J}$ Cancer 98: 1389-1397, 2008.

12. Saigusa S, Inoue Y, Tanaka K, Toiyama Y, Matsushita K, Kawamura M, Okugawa Y, Hiro J, Uchida K, Mohri Y, et al: Clinical significance of LGR5 and CD44 expression in locally advanced rectal cancer after preoperative chemoradiotherapy. Int J Oncol 41: 1643-1652, 2012.

13. Collett D: Modelling Survival Data in Medical Research. 3rd edition. CRC Press, London, 2015.

14. Chen S, Song X, Chen Z, Li X, Li M, Liu H and Li J: CD133 expression and the prognosis of colorectal cancer: A systematic review and meta-analysis. PLoS One 8: e56380, 2013.

15. Zhao Y, Peng J, Zhang E, Jiang N, Li J, Zhang Q, Zhang X and Niu Y: CD133 expression may be useful as a prognostic indicator in colorectal cancer, a tool for optimizing therapy and supportive evidence for the cancer stem cell hypothesis: A meta-analysis. Oncotarget 7: 10023-10036, 2016.

16. Horst D, Scheel SK, Liebmann S, Neumann J, Maatz S, Kirchner T and Jung A: The cancer stem cell marker CD133 has high prognostic impact but unknown functional relevance for the metastasis of human colon cancer. J Pathol 219: 427-434, 2009. 
17. Kemper K, Versloot M, Cameron K, Colak S, de Sousa e MeloF, de Jong JH, Bleackley J, Vermeulen L, Versteeg R, Koster J, et al: Mutations in the Ras-Raf Axis underlie the prognostic value of CD133 in colorectal cancer. Clin Cancer Res 18: 3132-3141, 2012.

18. Shmelkov SV, Butler JM, Hooper AT, Hormigo A, Kushner J, Milde T, St Clair R, Baljevic M, White I, Jin DK, et al: CD133 expression is not restricted to stem cells, and both $\mathrm{CD} 133^{+}$and CD133- metastatic colon cancer cells initiate tumors. J Clin Invest 118: 2111-2120, 2008.

19. Hongo K, Tanaka J, Tsuno NH, Kawai K, Nishikawa T, Shuno Y, Sasaki K, Kaneko M, Hiyoshi M, Sunami E, et al: CD133(-) cells, derived from a single human colon cancer cell line, are more resistant to 5-fluorouracil (FU) than CD133(+) cells, dependent on the $\beta 1$-integrin signaling. J Surg Res 175: 278-288, 2012.

20. Horst D, Kriegl L, Engel J, Kirchner T and Jung A: CD133 expression is an independent prognostic marker for low survival in colorectal cancer. Br J Cancer 99: 1285-1289, 2008.

21. Ueno H, Murphy J, Jass JR, Mochizuki H and Talbot IC: Tumour 'budding' as an index to estimate the potential of aggressiveness in rectal cancer. Histopathology 40: 127-132, 2002.

22. Ong CW, Kim LG, Kong HH, Low LY, Iacopetta B, Soong R and Salto-Tellez M: CD133 expression predicts for non-response to chemotherapy in colorectal cancer. Mod Pathol 23: 450-457, 2010.
23. Stanisavljević L, Myklebust MP, Leh S and Dahl O: LGR5 and CD133 as prognostic and predictive markers for fluoropyrimidine-based adjuvant chemotherapy in colorectal cancer. Acta Oncol 55: 1425-1433, 2016.

24. Sluiter N, de Cuba E, Kwakman R, Kazemier G, Meijer G and Te Velde EA: Adhesion molecules in peritoneal dissemination: Function, prognostic relevance and therapeutic options. Clin Exp Metastasis 33: 401-416, 2016

25. Chen J, Xia Q, Jiang B, Chang W, Yuan W, Ma Z, Liu Z and Shu X: Prognostic value of cancer stem cell marker ALDH1 expression in colorectal cancer: A systematic review and metaanalysis. PLoS One 10: e0145164, 2015.

26. Verwaal VJ, van Ruth S, Witkamp A, Boot H, van Slooten G and Zoetmulder FA: Long-term survival of peritoneal carcinomatosis of colorectal origin. Ann Surg Oncol 12: 65-71, 2005.

27. Nagata H, Ishihara S, Hata K, Murono K, Kaneko M, Yasuda K, Otani K, Nishikawa T, Tanaka T, Kiyomatsu T, et al: Survival and prognostic factors for metachronous peritoneal metastasis in patients with colon cancer. Ann Surg Oncol 24: 1269-1280, 2017.

(i) $($ This work is licensed under a Creative Commons

EY No No Attribution-NonCommercial-NoDerivatives 4.0 International (CC BY-NC-ND 4.0) License. 